\title{
A retrospective interventional study for evaluation of efficacy and safety of sildenafil citrate in improving intrauterine growth restriction and oligohydramnios using ultrasound Doppler velocimetry
}

\author{
Kedar N. Ganla ${ }^{1}$, Rana A. Choudhary ${ }^{1}$, Kavita N. Desai ${ }^{2}$, \\ Santoshi B. Kadam ${ }^{3}$, Krutika Arunachalam ${ }^{1}$
}

\begin{abstract}
${ }^{1}$ Department of Reproductive Medicine, Ankoor Fertility Clinic, Mumbai, India ${ }^{2}$ Dadar Imaging and Diagnostic Centre, Mumbai, India, ${ }^{3}$ Medical Services, Akumentis Healthcare Ltd., Thane, Maharashtra, India
\end{abstract}

Received: 14 October 2019 Accepted: 16 November 2019

\begin{abstract}
*Correspondence to: Dr. Kedar N. Ganla, Email: drkedarganla@ gmail.com
\end{abstract}

Copyright: (C) the author(s), publisher and licensee Medip Academy. This is an openaccess article distributed under the terms of the Creative Commons Attribution NonCommercial License, which permits unrestricted noncommercial use, distribution, and reproduction in any medium, provided the original work is properly cited.

\begin{abstract}
Background: Intrauterine growth restriction (IUGR) is one of the major reasons for neonatal morbidity and mortality. Oligohydramnios is a common finding in IUGR. In majority of these cases diminished utero-placental blood flow is observed. However, in spite of this understanding and identification of high-risk patients, the management options are limited. Sildenafil citrate, a phosphodiesterase type-5 inhibitor improves utero-placental perfusion.

Methods: We present a retrospective interventional study involving 50 adult pregnant women diagnosed with early-onset IUGR $(n=38)$ and oligohydramnios $(n=12)$. Vaginal sildenafil citrate $25 \mathrm{mg}$ t.i.d. was started from the day of diagnosis till delivery. Primary efficacy endpoints included changes in Doppler parameters i.e., amniotic fluid index (AFI), uterine artery (UA)- pulsatility index (PI), resistance index (RI) and systolic diastolic ratio (S/D ratio). Secondary endpoints included live birth, birth weight, Apgar score at birth, neonatal survival to hospital discharge and adverse maternal side effects.

Results: There was a statistically significant improvement in UA-PI, RI and $\mathrm{S} / \mathrm{D}$ ratios $(\mathrm{p}<0.0001)$ in all cases. In oligohydramnios cases, treatment showed a statistical significant increase in AFI score $(2.86 \pm 1.33 \mathrm{~cm})$. The mean birth weight on delivery was 2200 gm with good Apgar scores. No major adverse effects were reported by women using sildenafil citrate vaginally.

Conclusions: Sildenafil citrate, by increasing utero-placental perfusion, improves uterine artery Doppler patterns, AFI, fetal weight and overall better neonatal survival rates by reducing neonatal morbidity and mortality. Sildenafil citrate may hold a promising treatment strategy for management of IUGR and oligohydramnios.
\end{abstract}

Keywords: IUGR, Oligohydramnios, Sildenafil citrate, Utero-placental blood flow, Doppler

\section{INTRODUCTION}

Intrauterine growth restriction (IUGR) remains an important cause of perinatal and neonatal morbidity as well as mortality. ${ }^{1}$ Depending on the fetal stage of development, IUGR can be manifested as early symmetric or late asymmetric growth abnormality patterns, of which the latter is most common occurring in $70-80 \%$ of growth-restricted infants. ${ }^{2}$ Although knowledge of IUGR has increased dramatically with increase in ultra-sonographies and asymmetric IUGR have been studied extensively, there are no treatment options available. ${ }^{3}$ Oligohydramnios is a common finding in growth-restricted foetus and it is an important diagnostic parameter. Decreased amniotic fluid renders the umbilical cord vulnerable to compression, leading to variable decelerations, caesarean delivery, and possibly fetal death. ${ }^{4}$ Oligohydramnios can be defined as amniotic fluid volume $<5 \%$ for gestational age, amniotic fluid index (AFI) $<5 \mathrm{~cm}$ or maximal deepest pocket $<2 \mathrm{~cm} .{ }^{5}$ 
The most common placental condition leading to IUGR is due to alterations in the uteroplacental and fetal-placental circulations. In the majority of these cases, there is diminished maternal uteroplacental blood flow due to insufficient or incomplete trophoblastic invasion of the spiral arteries in the placental bed. ${ }^{6}$ Doppler velocimetry of the umbilical artery (UmA) estimates the resistance to blood perfusion of the fetoplacental unit. ${ }^{7}$ As IUGR worsens, Doppler abnormalities in these vascular territories also progressively worse. This presumed sequence and the anticipation of fetal deterioration form the basis for Doppler surveillance in IUGR. ${ }^{8}$ Currently there is no definitive modality for the management of IUGR foetus.

In normal pregnant woman, nitric oxide (NO) plays an important role in increasing the oxygen and nutrient supply to the foetus by influencing vasodilatation in the feto-placental circulation. Decreased NO availability may have an important role in the pathophysiology of IUGR. $\mathrm{NO}$ is produced from the amino acid (l-arginine) by NO synthases (NOS). NO increases the concentration of cyclic guanosine monophosphate (cGMP), which causes relaxation of the vascular smooth muscle. Drugs increasing the effect of NO may be possible therapeutic agents for IUGR. ${ }^{9}$ A reversible increased myometrial arterial tone by phosphodiesterase inhibition has been reported in vitro in pregnancies with fetal growth restriction and without preeclampsia. Sildenafil citrate acts by blocking phosphodiesterase-5 (PDE-5) that breaks down cGMP, consequently, mediating the vasodilator effects of NO. Sildenafil citrate increases uterine blood flow and potentiates estrogen-induced vasodilation. ${ }^{10} \mathrm{~A}$ promising effect of sildenafil citrate was seen in animal studies in the treatment of IUGR. ${ }^{11}$

The aim of this study is to analyse the effect of PDE5 inhibitor, sildenafil citrate in the management of IUGR and oligohydramnios.

\section{METHODS}

This was an observational, retrospective study conducted in a private Obstetrics and Gynaecology tertiary care clinic in Mumbai, India. All pregnant women conceived after infertility treatment and clinically diagnosed with IUGR or oligohydramnios in between April 2017 to December 2018 were observed. 50 eligible patient data were collected and analysed. The treatment charts of the patients fulfilling inclusion and exclusion criteria were reviewed.

\section{Inclusion criteria}

Age between 20-40 years, Gestational age of 28 weeks at the time of first Doppler, ultrasonography suggestive of IUGR (if estimated birthweight $<10^{\text {th }}$ percentile), oligohydramnios (AFI $<5 \mathrm{~cm}$ ) or other Doppler parameters suggestive of fetal insufficiency were included in the study.

\section{Exclusion criteria}

Women with a history of cardiovascular, renal or liver diseases, hypertension (blood pressure >130/90 $\mathrm{mmHg}$ ) prior to conception, known aneuploidy, anomaly in foetus or congenital infection, refusal to undergo Doppler studies or to undergo sildenafil treatment were excluded from the study.

Patients who met these criteria and agreed to use vaginal sildenafil citrate (Alivher® $25 \mathrm{mg}$ t.i.d.) for management of fetal growth restriction were included in the study.

Primary efficacy endpoints for this study were change in AFI, UmA pulsatility index (UmA PI), resistance index (UmA RI) and systolic diastolic ratio (UmA S/D). Secondary end-points noted for this study were eligibility to delivery interval, live birth, baby weight at birth, Apgar score, neonatal survival to hospital discharge duration, intact survival (i.e., survival to hospital discharge without any evidence of major complications like central nervous system (CNS) injury, grade 3 or 4 intraventricular haemorrhage or cystic periventricular leucomalacia, combined non-CNS severe morbidity (i.e., one or more bronchopulmonary dysplasia, grade 3 or above retinopathy of prematurity or necrotizing enterocolitis) and maternal side-effects (presence of vaginal discharge, itching and irritation over vulva). The treatment was initiated at the time of diagnosis of IUGR or oligohydramnios and was continued till 48 hours prior to planned delivery or 37 weeks of gestation, whichever was earlier. Decisions about pregnancy termination (either therapeutic abortion or delivery) were made using standard clinical assessments. Antenatal dexamethasone for fetal lung maturation was administered routinely once 'viability' was reached. All efficacy endpoints were measured before and after sildenafil citrate treatment. Foetuses and infants were followed until 28 days of life or primary hospital discharge, whichever was later. Women were followed until primary hospital discharge.

SAS 9.4® statistical software was used for programmed analysis of the statistical analysis. Continuous variables were summarized by number, mean, standard deviation, minimum, maximum and $95 \%$ confidence intervals. To analyze the absolute change in the efficacy endpoints a ttest was performed and $\mathrm{p}$-value derived. The $\mathrm{p}$-value of $<0.05$ was considered as statistically significant and pvalue of $<0.0001$ was considered as highly statistically significant. The decimal digit of minimum and maximum remains consistent with that recorded in the database. One more decimal digit will be kept for mean and median than the original data recorded in the database, and two more decimal digits will be kept for standard deviation.

\section{RESULTS}

All cases included in the study were in the age group of 20-40 years. The mean age of patients was $33.7 \pm 4.5$ years. Of the 50 included in the study, 38 had IUGR 
(abdominal circumference $<10^{\text {th }}$ percentile), $12 \mathrm{had}$ oligohydramnios (AFI $<5 \mathrm{~cm}$ ) and 36 had abnormal Doppler indices. Majority of the patients were nulliparous at the time of enrolment (42 out of 50 patients). Maternal characteristics at eligibility are as shown in (Table 1).

Table 1: Demographic characteristics.

\begin{tabular}{|ll|}
\hline Age (years) & $33.7 \pm 4.5$ \\
\hline GA at start (weeks) & $31.05 \pm 1.08$ \\
\hline IUGR $\left(\mathbf{A C}<\mathbf{1 0}^{\text {th }}\right.$ percentile) (n) & 38 \\
\hline Oligohydramnios $($ AFI $<\mathbf{5}$ cm) (n) & 12 \\
\hline Abnormal Doppler indices (n) & 36 \\
\hline
\end{tabular}

Among 38 IUGR cases, there was a statistically significant decrease $(\mathrm{p}<0.0001)$ in all Doppler indices i.e., UmA PI, RI and SD ratio before and after Sildenafil treatment as shown in (Table 2). This clearly shows that Sildenafil citrate significantly improves the uteroplacental perfusion.

Among 12 oligohydramnios cases also there was a statistically significant decrease $(\mathrm{p}<0.0001)$ in all
Doppler indices before and after sildenafil treatment as shown in (Table 3). There was an improvement in AFI by $2.86 \pm 1.33 \mathrm{~cm}$ which was highly statistically significant.

The mean gestational age at delivery was $34 \pm 4$ days. The mean gestational age at delivery could be prolonged by 35 days (gestational age at eligibility 218 days and gestational age at delivery 253 days). The mean birth weight on delivery was $2200 \mathrm{gm}$. In our study, there were no still births. All 50 women delivered and there were a total of 53 neonates, with 3 women delivering twins. The mode of delivery in the 50 enrolled women is summarized in (Table 4). 22 patients had vaginal delivery, 26 had C-section and rest 2 had vacuum delivery. All babies had good Apgar score at delivery (Table 5).

All neonates were followed up for 28 days after delivery. Of the 53 neonates, 13 required neonatal intensive care unit admission for low birth weight and prematurity, with average duration of hospital stay 12 days. There were 8 cases of neonatal jaundice and 6 neonates had feeding difficulties, but there were no other major complications due to prematurity or IUGR.

Table 2: Foetal Doppler indices before and after following sildenafil treatment among women with AC $<10$ th percentile.

\begin{tabular}{|llll|ll|}
\hline $\begin{array}{l}\text { Foetal } \\
\text { Doppler } \\
\text { indices }\end{array}$ & $\mathbf{N}$ & $\begin{array}{l}\text { Before drug intake } \\
(\text { Mean } \pm \text { SD })(95 \% \text { CL) }\end{array}$ & $\begin{array}{l}\text { After drug intake } \\
\text { (Mean } \pm \text { SD) }(\mathbf{9 5 \%} \text { CL) }\end{array}$ & $\begin{array}{l}\text { Absolute change } \\
\text { (Mean } \pm \text { SD) }(\mathbf{9 5 \%} \text { CL) })\end{array}$ & $\begin{array}{l}\text { P-value for } \\
\text { absolute } \\
\text { change }\end{array}$ \\
\hline AFI (cm) & 38 & $7.00 \pm 0.93(6.69-7.30)$ & $8.79 \pm 0.96(8.47-9.11)$ & $1.79 \pm 0.81(1.52-2.05)$ & $<0.0001$ \\
\hline UmA (PI) & 38 & $1.07 \pm 0.13(1.03-1.11)$ & $0.91 \pm 0.03(0.90-0.92)$ & $0.16 \pm 0.12(0.12-0.20)$ & $<0.0001$ \\
\hline UmA (RI) & 38 & $0.81 \pm 0.17(0.75-0.87)$ & $0.60 \pm 0.03(0.59-0.61)$ & $0.21 \pm 0.16(0.26-0.16)$ & $<0.0001$ \\
\hline UmA (S/D) & 38 & $3.91 \pm 1.07(3.56-4.26)$ & $2.78 \pm 0.26(2.69-2.86)$ & $1.13 \pm 0.89(1.42-0.84)$ & $<0.0001$ \\
\hline
\end{tabular}

Table 3: Foetal Doppler indices before and after following Sildenafil treatment among women with AFI $<5 \mathrm{~cm}$.

\begin{tabular}{|llllll|}
\hline $\begin{array}{l}\text { Foetal } \\
\text { Doppler } \\
\text { indices }\end{array}$ & $\mathbf{N}$ & $\begin{array}{l}\text { Before drug intake } \\
(\text { Mean } \pm \text { SD) }(\mathbf{9 5 \%} \text { CL) }\end{array}$ & $\begin{array}{l}\text { After drug intake } \\
\text { (Mean } \pm \text { SD) }(\mathbf{9 5 \%} \text { CL) }\end{array}$ & $\begin{array}{l}\text { Absolute change } \\
\text { (Mean } \pm \text { SD) } \text { (95\% CL) }\end{array}$ & $\begin{array}{l}\text { P-value for } \\
\text { absolute } \\
\text { change }\end{array}$ \\
\hline AFI (cm) & 12 & $3.97 \pm 0.35(3.74-4.19)$ & $6.83 \pm 1.19(6.07-7.59)$ & $2.86 \pm 1.33(2.02-3.71)$ & $<0.0001$ \\
\hline UmA (PI) & 12 & $1.25 \pm 0.08(1.20-1.30)$ & $0.95 \pm 0.06(0.92-0.99)$ & $0.29 \pm 0.11(0.22-0.36)$ & $<0.0001$ \\
\hline UmA (RI) & 12 & $0.98 \pm 0.10(0.92-1.04)$ & $0.62 \pm 0.02(0.60-0.63)$ & $0.36 \pm 0.09(0.42-0.30)$ & $<0.0001$ \\
\hline UmA (S/D) & 12 & $4.62 \pm 0.48(4.32-4.93)$ & $2.86 \pm 0.21(2.72-2.99)$ & $1.76 \pm 0.47(2.06-1.47)$ & $<0.0001$ \\
\hline
\end{tabular}

Table 5: Apgar score of the babies seen at 1, 5 and 10 minutes interval.

\begin{tabular}{|ll|}
\hline Apgar time & Average Apgar score \\
\hline $\mathbf{1}^{\text {st }}$ minute & $7.91 \pm 0.284$ \\
\hline $\mathbf{5}^{\text {th }}$ minute & $8.50 \pm 0.920$ \\
\hline $\mathbf{1 0}^{\text {th }}$ minute & $9.80 \pm 0.600$ \\
\hline
\end{tabular}

Table 6: Safety analysis.

\begin{tabular}{|llll|}
\hline Parameter & $\mathbf{N}$ & Present $(\boldsymbol{\%})$ & Absent (\%) \\
\hline Vaginal discharge & 50 & $4(8.00)$ & $46(92.00)$ \\
\hline Itching vulva & 50 & $2(4.00)$ & $48(96.00)$ \\
\hline Irritation over vulva & 50 & $2(4.00)$ & $48(96.00)$ \\
\hline
\end{tabular}


There were no major adverse effects amongst the women using sildenafil citrate vaginally like hypotension or visual disturbances. Very few reported increased vaginal discharge, itching over the vulva and irritation (Table 6). However, there was no discontinuation of therapy reported by these patients due to the side effects.

\section{DISCUSSION}

Restricted fetal growth results from pathophysiological and environmental factors. The major causes of IUGR are placental insufficiency, chronic placental infections, maternal diseases, abnormal genome and intravascular trophoblast invasion impairment. ${ }^{12}$ Various studies indicate placental insufficiency as one of the underlying causes leading to altered fetal growth and impaired placental capacity of delivering nutrients to the foetus has been shown to contribute to the etiology of IUGR. ${ }^{13}$

Sildenafil citrate, (pregnancy category B drug) a specific PDE-5 inhibitor, has been proposed as a potential therapeutic strategy to maintain placental function. ${ }^{10}$ It has emerged as a potential candidate for the treatment of intra-uterine growth restriction. By inhibiting PDE-5 enzyme activity, Sildenafil citrate increases cGMP and thereby release in NO. This dilates the myometrial small arteries leading to vasodilatation and improvement in placental perfusion. ${ }^{14}$ This improvement in perfusion leads to better transport of nutrients to the developing foetus and thus helps growth of IUGR foetus. As early as 2006, there were studies on use of sildenafil in IUGR on animal models. ${ }^{15}$ In a study on ovine model, sildenafil enhanced amino acid availability in the conceptus and improved foetal growth. ${ }^{16}$

Wareing demonstrated that sildenafil causes decrease in vasoconstriction and improved relaxation of fetal growth restriction small arteries thereby improving endothelial function of myometrial vessels. ${ }^{17}$ Later on Trapani et al showed that there was improvement in Doppler parameters and placental insufficiency remote from term which was demonstrated by decrease in PI of uterine and umbilical arteries in human foetus with IUGR. ${ }^{18}$ Villanueva-Garcia et al conducted a systematic review of experimental and clinical studies of sildenafil citrate for IUGR and pre-term which showed that sildenafil reduced uterine artery impedance and improved IUGR. ${ }^{19}$ Use of sildenafil citrate does not appear to cause any severe adverse maternal side effects nor any increase in the rate of stillbirths, neonatal deaths, or congenital anomalies. ${ }^{20}$

There have been cases reports about the use of sildenafil in early onset IUGR. ${ }^{21}$ Some have also shown that in cases of previous pregnancy losses and thin endometrium, vaginal sildenafil citrate improved the uterine artery blood flow and endometrial thickness and hence reduced the chances of miscarriages. In our study we introduced vaginal sildenafil citrate in the late second trimester. Our study demonstrated that the mean of the UmA PI, RI, and S/D ratio significantly improved after sildenafil citrate therapy in all cases of IUGR and Oligohydramnios.

In our study all 50 women delivered with a total of 53 neonates, with 3 women delivering twins. We were able to prolong the gestational age at delivery and avoid preterm induction for severe IUGR or Oligohydramnios by an average of 35 days and hence avoid the complications due to prematurity in those foetuses.

A very recent systematic meta-analysis by Paauw which included 22 animal studies and two human randomized control trials concluded that sildenafil increases fetal growth during IUGR or preeclampsia with a positive relation up to a human equivalent dose of $450 \mathrm{mg} / \mathrm{d}$. It further showed that sildenafil had significant blood pressure lowering effect during IUGR or preeclampsia pregnancy. ${ }^{11}$

A limitation of this study is that the participating women treated with vaginal sildenafil citrate may have differed in from the general population as they conceived after treatment for infertility and we are underpowered to demonstrate this statistically. This study is further limited by the fact that we did not measure maternal serum sildenafil concentrations during therapy to compare the in vivo concentration with the effective concentrations known to dilate maternal utero-placental vascular endothelium on wire myography. The long term morbidity and mortality could not be studied and future studies in this direction are needed.

In summary, our data suggest that early diagnosis of women at risk for IUGR and oligohydramnios particularly conceived after infertility treatment is important. Sildenafil treatment may offer a new opportunity to improve perinatal outcome in asymmetric IUGR. However, these data are not sufficient to firmly guide decision making about the use of sildenafil citrate in pregnancies complicated by early-onset IUGR and future randomized trials are needed to validate its use and safety.

\section{ACKNOWLEDGEMENTS}

The authors are grateful to Dr. Prashant Palkar of Akumentis Healthcare Ltd. for providing technical help and writing assistance for this study.

Funding: No funding sources

Conflict of interest: None declared

Ethical approval: The study was approved by the Institutional Ethics Committee

\section{REFERENCES}

1. Sharma D, Shastri S, Sharma P. Intrauterine growth restriction: antenatal and postnatal aspects. Clin Med Insights Pediatr. 2016;10:67-83.

2. Moh W, Graham JM, Wadhawan I, Sanchez-Lara PA. Extrinsic factors influencing fetal deformations 
and intrauterine growth restriction. J Pregnancy. 2012;2012:750485.

3. Saw SN, Tay JJH, Poh YW, Yang L, Tan WC, Tan LK, et al. Altered placental chorionic arterial biomechanical properties during intrauterine growth restriction. Sci Rep. 2018;8(1):16526.

4. Chauhan SP, Taylor M, Shields D, Parker D, Scardo JA, Magann EF. Intrauterine growth restriction and oligohydramnios among high-risk patients. Am J Perinatol. 2007;24(4):215-21.

5. Sharma ST. Clinical study of maternal and fetal outcome inpregnancies with Oligohydramnios. MedPulse - Int J Gynaecol. 2019;11(2):60-4.

6. Krishna U, Bhalerao S. Placental insufficiency and fetal growth restriction. J Obstet Gynaecol India. 2011;61(5):505-11.

7. Society for Maternal-Fetal Medicine Publications Committee, Berkley E, Chauhan SP, Abuhamad A. Doppler assessment of the fetus with intrauterine growth restriction. Am J Obstet Gynecol. 2012;206(4):300-8.

8. Turan OM, Turan S, Gungor S, Berg C, Moyano D, Gembruch U, et al. Progression of Doppler abnormalities in intrauterine growth restriction. Ultrasound Obstet Gynecol. 2008;32(2):160-7.

9. Chen J, Gong X, Chen P, Luo K, Zhang X. Effect of L-arginine and sildenafil citrate on intrauterine growth restriction fetuses: a meta-analysis. BMC Pregnancy Childbirth. 2016;16:225.

10. Dastjerdi MV, Hosseini S, Bayani L. Sildenafil citrate and uteroplacental perfusion in fetal growth restriction. J Res Med Sci. 2012;17(7):632-6.

11. Paauw ND, Terstappen F, Ganzevoort W, Joles JA, Gremmels H, Lely AT. Sildenafil During pregnancy: a preclinical meta-analysis on fetal growth and maternal blood pressure. Hypertens. 2017;70(5):9981006.

12. Giuliano N, Annunziata ML, Tagliaferri S, Esposito FG, Imperato OC, Campanile $\mathrm{M}$, et al. IUGR management: new perspectives. J Pregnancy. 2014;2014:620976.

13. Gaccioli F, Lager S. Placental nutrient transport and intrauterine growth restriction. Front Physiol. 2016;16(7):40.

14. El-Sayed MA, Saleh SA, Maher MA, Bayome AMK. Effect of sildenafil citrate on uteroplacental perfusion
Doppler indices in growth-restricted fetuses. Menoufia Med J. 2018;31:31-7.

15. Refuerzo JS, Sokol RJ, Aranda JV, Hallak M, Hotra JW, Kruger M, et al. Sildenafil citrate and fetal outcome in pregnant rats. Fetal Diagn Ther. 2006;21(3):259-63.

16. Satterfield MC, Bazer FW, Spencer TE, Wu G. Sildenafil citrate treatment enhances amino acid availability in the conceptus and fetal growth in an ovine model of intrauterine growth restriction. J Nutr. 2010;140(2):251-8.

17. Wareing M, Myers JE, O'Hara M, Baker PN. Sildenafil citrate (Viagra) enhances vasodilatation in fetal growth restriction. J Clin Endocrinol Metab. 2005;90(5):2550-5.

18. Trapani A, Gonçalves LF, Trapani TF, Franco MJ, Galluzzo RN, Pires MM. Comparison between transdermal nitroglycerin and sildenafil citrate in intrauterine growth restriction: effects on uterine, umbilical and fetal middle cerebral artery pulsatility indices. Ultrasound Obstet Gynecol. 2016;48(1):61-5.

19. Villanueva-García D, Mota-Rojas D, HernándezGonzález R, Sánchez-Aparicio P, Alonso-Spilsbury $\mathrm{M}$, Trujillo-Ortega ME, et al. A systematic review of experimental and clinical studies of sildenafil citrate for intrauterine growth restriction and pre-term labour. J Obstet Gynaecol. 2007;27(3):255-9.

20. Dunn L, Greer R, Flenady V, Kumar S. Sildenafil in pregnancy: a systematic review of maternal tolerance and obstetric and perinatal outcomes. Fetal Diagn Ther. 2017;41(2):81-8.

21. Choudhary R, Desai K, Parekh H, Ganla K. Sildenafil citrate for the management of fetal growth restriction and oligohydramnios. Int $\mathbf{J}$ Womens Health. 2016;8:367-72.

Cite this article as: Ganla KN, Choudhary RA, Desai KN, Kadam SB, Arunachalam K. A retrospective interventional study for evaluation of efficacy and safety of sildenafil citrate in improving intrauterine growth restriction and oligohydramnios using ultrasound Doppler velocimetry. Int J Basic Clin Pharmacol 2019;8:2736-40. 